\title{
Subclinical Hypothyroidism in Children: Normal Variation or Sign of a Failing Thyroid Gland?
}

\author{
Paul B. Kaplowitz \\ Division of Endocrinology, Children's National Medical Center, George Washington University School of Medicine and Health Sciences, \\ Washington, DC 20010, USA \\ Correspondence should be addressed to Paul B. Kaplowitz, pkaplowi@cnmc.org
}

Received 19 January 2010; Accepted 5 April 2010

Academic Editor: Horacio Domené

Copyright () 2010 Paul B. Kaplowitz. This is an open access article distributed under the Creative Commons Attribution License, which permits unrestricted use, distribution, and reproduction in any medium, provided the original work is properly cited.

Subclinical hypothyroidism (SCH), defined by a normal total or free T4 level and a mildly elevated TSH (typically 5-10 mU/L), is common in children, but there is currently no consensus on management. Several recent pediatric studies indicate that progression of SCH to overt hypothyroidism $(\mathrm{OH})$ is uncommon and that over a period of several years, elevated TSH usually either normalizes or persists but does not increase. The etiology appears to be multifactorial, with some cases representing minor developmental abnormalities, some related to obesity, some to mild autoimmune thyroiditis, and some associated with mutations in the gene for the TSH-receptor. There are no pediatric studies showing clinical benefit of treating these children with thyroid hormone, but additional studies in this area are needed. Since few cases of pediatric SCH progress to $\mathrm{OH}$, treatment can be deferred, and periodic follow-up testing may be the preferred strategy, with elevated thyroid antibodies or a goiter being considered risk factors for eventual $\mathrm{OH}$.

\section{Introduction}

Primary care physicians and pediatric endocrinologists frequently face the decision of what to do about the child who has a normal total or free T4 level and a slightly elevated TSH (typically $5-10 \mathrm{mU} / \mathrm{L}$ ), a situation usually referred to as subclinical hypothyroidism (SCH) [1]. The reasons for ordering the tests in the first place vary, but many primary care physicians believe that prompt evaluation and treatment are essential. The response of pediatric endocrinologists may range from a decision to start thyroid hormone immediately after confirmation of the elevated TSH, to recommending frequent monitoring of TSH for prolonged periods, to the suggestion that unless a follow-up test shows a further significant rise in TSH or a subnormal free T4, no action should be taken.

There are several reasons for this lack of consensus among pediatric endocrinologists. First, there have been until recently a scarcity of studies reporting on the natural history of SCH in children; thus there has been concern that if untreated, $\mathrm{SCH}$ will frequently progress to overt hypothyroidism $(\mathrm{OH})$. $\mathrm{OH}$ will be defined here as a low total or free
T4 with a TSH of $>20 \mathrm{mU} / \mathrm{L}$, which all clinicians would agree requires treatment, though occasionally one encounters a clearly low free T4 with a TSH in the $10-20 \mathrm{mU} / \mathrm{L}$ range. There are no controlled pediatric studies (as there are in adults) looking at outcomes of children with $\mathrm{SCH}$ treated with l-thyroxine versus those given placebo. Furthermore, there is a high risk of developmental delay in infants who have untreated severe congenital hypothyroidism (low T4 and TSH usually $>100$ ). Since many children with SCH are identified during newborn screening or during the first year of life, physicians may be concerned that failing to treat $\mathrm{SCH}$ will expose the child to the risk of developmental delay if $\mathrm{OH}$ develops later or that treatment is needed to prevent growth retardation [1].

The cost implications of the decision to treat or not to treat an individual child with thyroid hormone may seem small, considering that thyroid hormone costs only $\$ 100$ $\$ 200$ per year depending on whether one uses generic 1thyroxine or a brand. However, the decision to treat a child with SCH long term may involve a lifetime of thyroid hormone replacement and frequent monitoring of total or free T4 and TSH levels. At a widely used commercial lab, the 
cost of a free T4 is $\$ 144$, and the TSH test costs $\$ 170$; during the first years of life, it is typical for tests to be repeated every few months, with less frequent but at least annual testing as the child gets older.

This paper will summarize what we know about the natural history of SCH in children and will explore some of the etiologies for both transient and persistent mild elevation of TSH. While brief reference will be made to adult studies on SCH, it is important to point out why one cannot simply extrapolate adult data to children. Many children with $\mathrm{SCH}$ are identified at a young age, so the elevated TSH is often not an acquired condition due to mild autoimmune thyroiditis, as is typically the case in adults, but likely a mild, compensated congenital condition.

\section{Why Are Thyroid Tests Ordered So Frequently?}

One key reason $\mathrm{SCH}$ appears to be so common in children is that an increasing number of children undergo thyroid testing. Thyroid tests are most helpful in the child with a newly detected goiter or when there are more than one of the classic symptoms of hypothyroidism or hyperthyroidism. In practice, thyroid tests are often ordered in situations where $\mathrm{OH}$ is unlikely to be found, including (1) as part of a lab evaluation for obesity, (2) in the work-up of fatigue with no goiter and no other symptoms of hypothyroidism, (3) in children with a family history of hypothyroidism, (4) in short healthy children with normal growth rates, (5) in patients about to start or patients taking psychoactive medications, (6) in children with precocious or delayed puberty, and (7) in girls with irregular menses. One study from Germany looked at thyroid tests in over 1400 patients evaluated for obesity and reported hypothyroidism in only $0.3 \%$, indicating the low yield in screening this population [2]. A recent study from one insurance company in Israel found that $24 \%$ of 12-16 year old children had at least one TSH ordered over a 5-year period, a very high proportion [3].

\section{Natural History Studies of SCH in Children (Summarized in Table 1)}

Many cases of SCH in children are identified in the newborn period due to screening for congenital hypothyroidism. A longitudinal study from Italy followed a group of 44 infants identified with elevated TSH on newborn screening, whose follow-up TSH at a mean of 22 days of life was either normal ( $<5 \mathrm{mU} / \mathrm{L} ; 23$ infants) or mildly elevated (5-12 mU/L; 21 infants) [4]. All of the 16 children who had TSH levels $<4.0 \mathrm{mU} / \mathrm{L}$ at $16-44$ months continued to have normal TSH at $4.1-6.6$ years and at 7.2-9.5 years. Of the 28 whose TSH levels were in the $4-11 \mathrm{mU} / \mathrm{L}$ range at $16-44$ months, $1 / 3 \mathrm{had}$ their TSH normalized during prolonged follow-up, but $2 / 3$ had persistent TSH elevation. Twenty of 28 were treated with 1-thyroxine and then withdrawn from treatment 2 months before retesting; none had a TSH $>10 \mathrm{mU} / \mathrm{L}$ off treatment. Thyroid ultrasound revealed hypoplasia of one lobe or thyroid hemiagenesis or goiter in half the subjects. The authors concluded that mild TSH elevation in the newborn period may be a marker for significant congenital anatomic or thyroid function abnormalities and that such children are at high risk for persistent TSH elevation. However, since none of their subjects developed $\mathrm{OH}$ during follow-up of up to 9.5 years, the practical significance of these congenital abnormalities is not clear.

A novel approach to studying the outcome of mild TSH elevation was taken by an Israeli group, who used a database of 121,000 children followed by a single organization who had a TSH done in 2002 [3]. Patients who had both a low free $\mathrm{T} 4$ and $\mathrm{TSH}>10 \mathrm{mU} / \mathrm{L}$ at the initial screening or during follow-up (only $0.4 \%$ ) were treated. There were $2.9 \%$ whose initial TSH was $>5.5$ to $10 \mathrm{mU} / \mathrm{L}$, and over the subsequent 5 years $73.6 \%$ had the TSH normalize, in $1 / 4$ it remained borderline, and it rarely increased to $>10$ during subsequent testing. For patients with a normal free T4 and $\mathrm{TSH}>10 \mathrm{mU} / \mathrm{L}$ who were not treated, the second TSH was normal in $40 \%$, decreased to the mildly elevated range in $33 \%$, and remained $>10 \mathrm{mU} / \mathrm{L}$ in only $25 \%$.

In a recent prospective follow-up study of 92 Italian children ages 5-15 with "idiopathic" SCH (no goiter and negative thyroid antibodies) [5], 38 patients had normalization of TSH (none in the first 6 months, 16 between 6 and 12 months and 22 between 12 and 24 months). There were 54 patients $(59 \%)$ whose $\mathrm{TSH}$ remained elevated in the 5-10 range, and only 11 patients had TSH increase to $>10 \mathrm{mU} / \mathrm{ml}$; in all cases it was between $10.5-15 \mathrm{mU} / \mathrm{L}$. Free T4 levels remained normal in all patients. No lab test done at baseline was predictive of either normalization or a further increase in TSH.

The most common cause of acquired $\mathrm{OH}$ in both children and adults is autoimmune or Hashimoto's thyroiditis (AIT). Moore [6] reported on 18 children (mostly age 1019) who had mild to significant TSH elevation (as high as $60 \mathrm{mU} / \mathrm{L}$ ), normal T4, positive thyroid antibodies, and in some cases a goiter. Eleven were monitored off treatment and 7 were treated for 5-10 years and then retested after at least 1 year off treatment. In 7 patients, TSH normalized, in 10 patients it remained mildly to moderately elevated but with a normal T4, and only a single patient had both a low T4 and elevated TSH. Three patients in the treated group with initial TSH in the 50-64 range had normal T4 and TSH in the 3-10 range off therapy. This small study shows that $\mathrm{SCH}$ due to AIT can persist for years without progression to $\mathrm{OH}$ and that patients with moderate TSH elevation may have a recovery of thyroid function over time.

A larger study of the natural history of children with AIT from Italy examined 160 children with positive thyroid antibodies, ultrasonography of the thyroid compatible with AIT, and TSH either normal or 100-200\% of the upper limit of normal (ULN) [7]. Patients were treated if their TSH increased to $>200 \%$ ULN or followed for at least 5 years. In the 55 patients with TSH $100-200 \%$ of the ULN at the first visit, TSH normalized in $29 \%$, remained mildly elevated in $29 \%$, and became elevated to $>200 \%$ of the ULN in $42 \%$. Since treatment was started as soon as TSH exceeded $200 \%$ of the ULN, it was not clear what proportion actually would have developed $\mathrm{OH}$ with a low free T4. Although larger 
TABLE 1: Natural history studies of subclinical hypothyroidism in children.

\begin{tabular}{|c|c|c|c|c|}
\hline Patient population & $\mathrm{N}$ with $\mathrm{SCH}$ & Years of $\mathrm{f} / \mathrm{u}$ & Outcomes & Ref \\
\hline Abnormal newborn screening TSH & 28 & $7.2-9.5$ years & $\begin{array}{l}9 \text { with normal TSH } \\
19 \text { with TSH } 4-10 \\
0 \text { with TSH }>10\end{array}$ & {$[4]$} \\
\hline $\begin{array}{l}\text { Children in a single health care system } \\
\text { screened in 2002; no known thyroid disease }\end{array}$ & 3,475 & Up to 5 years & $\begin{array}{l}73.6 \% \text { with normal TSH } \\
\approx 25 \% \text { with } \mathrm{TSH} 5.5-10 \\
\approx 2 \% \text { with } \mathrm{TSH}>10\end{array}$ & {$[3]$} \\
\hline Idiopathic SCH—no antibodies, no goiter & 92 & 2 years & $\begin{array}{l}38 \text { with normal TSH } \\
43 \text { with TSH 5-10 } \\
11 \text { with TSH > } 10(10.5-15)\end{array}$ & {$[5]$} \\
\hline $\begin{array}{l}\text { Autoimmune thyroiditis: } \mathrm{nl} \mathrm{T4} \text { and TSH } \\
\text { 5-64 mU/L }\end{array}$ & 18 & Mean of 5.8 years & $\begin{array}{l}7 \text { with normal TSH } \\
10 \text { with normal T4, } \uparrow \text { TSH } \\
1 \text { with low T4, } \uparrow \text { TSH }\end{array}$ & {$[6]$} \\
\hline Autoimmune thyroiditis & 55 & At least 5 years & $\begin{array}{l}16 \text { with normal TSH } \\
16 \text { with TSH 1-2x ULN } \\
23 \text { with TSH > 2x ULN }\end{array}$ & {$[7]$} \\
\hline $\begin{array}{l}\text { Patients with SCH maintained on low doses } \\
\text { of l-thyroxine }\end{array}$ & 30 & $\begin{array}{l}\text { Mean of } 3.5 \text { years on } \\
\text { 1-thyroxine then stopped }\end{array}$ & $\begin{array}{l}14 \text { with TSH }<5 \\
12 \text { with TSH 5-9.9 } \\
4 \text { with TSH } 10-15\end{array}$ & {$[9]$} \\
\hline Down syndrome: mean age $16.4 \pm 10$ years & 70 & $2-7$ years & $\begin{array}{l}19 \text { with normal TSH } \\
46 \text { with SCH } \\
3 \text { with overt hypothyroidism } \\
2 \text { with hyperthyroidism }\end{array}$ & [10] \\
\hline
\end{tabular}

thyroid volume and increased thyroglobulin antibodies were somewhat predictive of deterioration of thyroid function for the group as a whole, no parameters predicted the course in individual patients.

In a series of 23 children with AIT based on one positive thyroid antibody and the typical ultrasonographic pattern (usually a heterogeneous and hypoechogenic pattern) [8], there were 7 euthyroid patients, 14 with $\mathrm{SCH}$ and 2 with $\mathrm{OH}$. Euthyroid patients had persistently normal TSH during a median of 4.7 years of follow-up. Patients with $\mathrm{SCH}$ and $\mathrm{OH}$ were treated with l-thyroxine for a median of 6.4 years. After withdrawal from therapy, 10/14 children with SCH had TSH levels very close to initial levels, 3 patients with initial TSH $13.7 \pm 3$ had normalization of TSH $(2.7 \pm 0.7)$, and only one of 14 had worsening thyroid function.

The author recently analyzed a group of 30 children started on l-thyroxine when they had normal total or free T4 but a mildly to moderately elevated TSH (range of 5-40 mU/L). These selected children did not require increases in 1-thyroxine dose over time (in some cases it was decreased), and TSH remained normal on $25-50 \mathrm{mcg} / \mathrm{day}$ [9]. Seventeen of the 30 were started on treatment in the first year of life (10 in the first 2 months), and 6 had Down syndrome. They were treated for a mean of 3.5 years (range 0.5-8.5 years). After at least one month off treatment, most children had slightly lower but still normal free T4 levels; $14 / 30$ had TSH $<5 \mathrm{mU} / \mathrm{L}, 12 / 30$ had TSH $5.0-9.9 \mathrm{mU} / \mathrm{L}$, and 4 had TSH $10-15 \mathrm{mU} / \mathrm{L}$. None had a TSH higher than the initial level which prompted initiation of therapy, and none developed typical hypothyroid symptoms. This study, like the ones cited above, suggests that most children with normal free T4 and mildly elevated TSH, many identified in the first year of life, do not have a clinical course of progressive thyroid failure.

\section{SCH in Down Syndrome and Other Syndromes}

It has been long known that $\mathrm{SCH}$ is particularly common in children with Down syndrome. Rubello et al. reported that $32.5 \%$ of a group of 344 Italian Down syndrome children had SCH and that thyroid antibodies were not much more likely to be found in this group $(18.7 \%)$ than in Down syndrome patients with normal TSH (15.7\%) [10]. During a mean of 3 years of follow-up of 70 patients, TSH normalized in $27 \%$ and remained mildly elevated in $66 \%$; overt hypothyroidism developed in $7 \%$ and hyperthyroidism in $4 \%$, but only in the subset of patients who were antibody positive (Table 1). Another study of 137 children with Down syndrome found 4 cases of congenital hypothyroidism (3\%), 8 cases $(6 \%)$ of acquired $\mathrm{OH}$, and 4 cases $(3 \%)$ of hyperthyroidism [11]. All of the acquired $\mathrm{OH}$ children and the hyperthyroid children had positive thyroid peroxidase antibodies. There were an additional 53 cases (39\%) with normal T4 and mildly elevated TSH (5-13 mU/L), of whom $24 \%$ had positive antibodies, compared with $13 \%$ positive antibodies in children with TSH $<5 \mathrm{mU} / \mathrm{L}$. No improvement in growth velocity was found in the 9 patients with mild TSH elevation who were treated with l-thyroxine. The etiology of the high frequency of SCH in Down syndrome is unknown. Tonacchera et al. did not find inactivating mutations of the TSH-receptor in 12 Down syndrome children with elevated TSH [12], and Konings et al. found no evidence for a TSH 
with reduced biological activity in serum from children with Down syndrome compared to normal children [13].

In a study of 92 children with William syndrome between the ages of 0.2 and 17 years, none were found to have $\mathrm{OH}$, but $31.5 \%$ had $\mathrm{SCH}$, with negative thyroid antibodies and stable thyroid function over time [14]. Thyroid function has also been evaluated in detail in a large group of 120 subjects from infancy to age 32 with the chromosome 18 q-syndrome. There were $12 \%$ with primary hypothyroidism and several patients were found who fit the definition of $\mathrm{SCH}$, but the frequency of $\mathrm{SCH}$ in this population was not defined [15].

\section{Does SCH Cause Symptoms and Is Treatment Beneficial?}

There is an almost complete lack of pediatric randomized controlled trial data on this subject so one is obligated to refer to adult studies. The debate over treatment of adult $\mathrm{SCH}$ has persisted for years, and review articles have been published. In 2001, the Journal of Clinical Endocrinology aired both sides of the debate, with one article taking the position "Subclinical hypothyroidism is mild thyroid failure and should be treated" [16] and the other article stating "The treatment of subclinical hypothyroidism is seldom necessary" [17]. In the latter article, studies were reviewed which examined the effect of treatment of SCH on improved quality of life, blood lipid levels, or resolution of hypothyroid symptoms. While some studies do appear to show slight improvement in lipid levels with treatment, a rigorous analysis indicates that for studies which included only subjects with TSH in the 4.5-10 mU/L range, no benefit was seen. In 2005, a consensus statement was published jointly by the American Association of Clinical Endocrinologists, the American Thyroid Association, and The Endocrine Society which concluded after review of the evidence and an opinion survey of thyroid specialists that treatment of patients with SCH with TSH levels of 4.5-10 mU/L was appropriate [18]. However, in the same issue, the chairman of the panel appointed by the 3 societies voiced disagreement with the consensus statement [19], concluding that the only adverse outcome of not treating adults with $\mathrm{SCH}$ was development of $\mathrm{OH}$ at a rate of $2.6 \%$ per year in patients without thyroid peroxidase antibodies and $4.3 \%$ per year in the presence of thyroid antibodies, based on data from the Wickham survey of thyroid disease in the community [20].

Since thyroid hormone is important for brain development in young children, the effect of SCH and its treatment on cognitive development would be of interest. One report used data from the Third National Health and Nutrition Examination Survey (NHANES III) which included 1327 adolescents ages $13-16$, of whom $1.7 \%(n=22)$ had SCH [21]. Curiously, the mean reading and block design scores in the SCH children were higher than for the 1275 euthyroid subjects, though the clinical significance is not clear. One treatment study looked at 11 children ( 8 with congenital $\mathrm{SCH}$ and 3 with acquired $\mathrm{SCH}$ ) who had a battery of tests off and on thyroid hormone replacement for an average of
91 days and no differences in neuropsychological test scores were found [21].

Severe acquired hypothyroidism can result in slow growth and short stature. A recent study from Brazil looked at thyroid tests in 367 short children (average age 10.9 years) with no defined cause. SCH was found in 46 patients or $12.5 \%$, but there was no difference in total T4 level or height SD score between the short children with $\mathrm{SCH}$ and those with normal TSH [22]. The authors treated 20 of the $46 \mathrm{SCH}$ children SCH with 1-thyroxine for 12 months; there was no significant difference in growth velocity between the treated and untreated SCH children, and the control short children with normal TSH [23].

In the absence of any evidence that treatment of $\mathrm{SCH}$ in children is beneficial, some clinicians take the view that since severe untreated $\mathrm{OH}$ can cause developmental delay in newborns and slowing of growth in older children, one should err on the side of caution. This view is summarized in a 2007 commentary [24], proposing that thyroid antibodies and ultrasound can be performed in all children with $\mathrm{SCH}$ and that "because the potential harm of early treatment appears to be so minor and limited, it seems prudent to err on the side of provisional diagnosis and early treatment rather than wait until sufficient information is available to determine the issue of whether to treat or not."

\section{Etiology of Subclinical Hypothyroidism}

Since most recent longitudinal studies show that at about $1 / 3$ of patients with SCH have normalization of TSH over time whereas most of the remainder have persistent mild TSH elevation, causes of SCH will be considered in these 2 distinct subgroups.

\subsection{Transient SCH}

(1) Random TSH Variation. TSH levels in healthy individuals tend to fluctuate during the day as well as over time. One study compared early morning fasting and late morning TSH levels in 100 patients. In 97, TSH declined during the morning, by a mean of 26\% [25]. If we define a TSH of $>5.0 \mathrm{mU} / \mathrm{L}$ as abnormal, a child could have a TSH of $6.0 \mathrm{mU} / \mathrm{L}$ on one occasion and $4.0 \mathrm{mU} / \mathrm{L}$ when repeated later (particularly if done at a different time of day) with no real change in thyroid status. Although one might conclude that SCH had "resolved", the TSH remains in the range which may be normal for that child but mildly elevated for the general population.

(2) Non-Thyroidal Illness. A child with an active or recent acute illness may have a transient drop in thyroid hormone production. During the recovery phase, a transient increase in TSH is the normal mechanism for restoring normal free T4 levels, and TSH will return to normal within a short period of time.

(3) Mild AIT Which Recovers or Improves. As noted above $[6,8]$, pediatric AIT does not inevitably destroy 
the thyroid but may go into remission, allowing the thyroid gland to recover and TSH to normalize, even in cases where enlargement of the thyroid gland persists.

\subsection{Persistent SCH}

(1) The normal TSH range is defined as range in which $95 \%$ of values in healthy people fall; thus about $2.5 \%$ of normal individuals will have and maintain a TSH at or slightly above the upper end of the normal range.

(2) Mild Developmental Thyroid Abnormalities. The study which followed children with mild TSH elevation found on newborn screening [4] identified 8 of 19 children with hypoplasia of one lobe or hemiagenesis of the thyroid. If these minor developmental abnormalities are functionally related to the TSH elevation, there appears to be a sufficient amount of thyroid tissue to sustain normal thyroid hormone production for many years. Whether TSH levels would increase in such patients after the pubertal growth spurt, when there is often an increase in thyroid hormone requirement, is not known.

(3) Children Born Small for Gestational Age. A recent study from Argentina of 53 children born SGA, with mean age $5.6 \pm 3.2$ years, impaired catch-up growth, and negative thyroid antibodies, found that $1 / 2$ had an exaggerated TSH response to thyrotropin releasing hormone (TRH) compared to control children. Both groups had identical mean free T4 levels but the group with exaggerated $\mathrm{TRH}$ response had a mean TSH of $6.2(4.2-14.6)$ versus $3.2(1.6-7)$ in the normal TRH response group. The authors speculate that children with intrauterine growth retardation may develop abnormal TSH regulatory circuitry characterized by an abnormal TSH set point without alteration in thyroid function [26].

(4) Mild Stable Autoimmune Thyroiditis. Although it seems more likely that AIT would over time either resolve or cause thyroid failure, there may be a variant form of AIT in which the gland's minimally impaired ability to produce thyroid hormone remains stable over a long period of time.

(5) Obesity. There have been several reports linking obesity to increased TSH. The best of these, a study of 86 patients at the Cleveland Clinic who underwent weight reduction surgery, found that prior to surgery, $10.5 \%$ had thyroid tests consistent with $\mathrm{SCH}$ and there was a strong correlation between BMI and TSH [27]. Following weight loss surgery with a mean decrease in BMI from 49 to $32 \mathrm{~kg} / \mathrm{m}^{2}$, mean TSH decreased from 4.5 to $1.9 \mathrm{mU} / \mathrm{L}$ with no change in free T4 levels. A pediatric study which looked at multiple factors involved in $\mathrm{SCH}$ reported that $28.4 \%$ of 88 patients with $\mathrm{SCH}$ and negative thyroid antibodies were obese or overweight [28]. While the mechanism for obesity-related elevation of TSH has not been elucidated, it is not surprising that when screening obese children for thyroid disease, $\mathrm{SCH}$ is found far more often than $\mathrm{OH}$.

(6) Mutations in the TSH-Receptor (TSH-R). A breakthrough in understanding $\mathrm{SCH}$ has come from studies showing that some children with $\mathrm{SCH}$ have defined mutations in the TSH-receptor (TSH-R) gene. A recent study from Japan examined 102 children with permanent TSH elevation found on newborn screening; $3 / 70$ with TSH $>10 \mathrm{mU} / \mathrm{L}$ had mutations in each of the 2 TSH-R genes, and 3/32 with TSH 5-10 mU/L had single mutations in the TSH-R gene [29]. In the study from Italy cited above [25], of their 88 pediatric SCH subjects, 10 had mutations where an effect on TSH-receptor signaling had been found in previous studies; most of the TSH-R mutations is this study were found in one allele. In the most recent report on the subject, TSH$\mathrm{R}$ mutations were found in 11 of 39 or $28 \%$ of a group of 39 children with nonautoimmune SCH. Three of the subjects had hypoplastic glands on ultrasound [30]. These observations provide a logical explanation as to why many of children with $\mathrm{SCH}$ are identified in the newborn period and why their TSH remains so stable over many years of followup. If the TSH-receptor has a reduced ability to bind or be activated by TSH, it may take 2-4 times the normal amount of TSH to optimally activate the TSH-receptors (i.e., mild TSH resistance).

\section{Conclusions from Literature Review}

The weight of evidence from the above studies points to most cases of persistent SCH representing stable alterations of the child's pituitary-thyroid axis such that normal free T4 levels are maintained over a period of many years in the presence of slightly elevated TSH levels. It is notable how infrequently $\mathrm{SCH}$ progress to $\mathrm{OH}$ over time, even in those children with features suggestive of AIT where such progression should be common. While only a minority of SCH patients may have mutations of the TSH-R, that situation provides the clearest example for what may prove to be the underlying physiology of most cases of persistent pediatric SCH: euthyroidism with (for a variety of reasons both congenital and acquired) a mild elevation of TSH.

\section{Suggestions for Management of SCH}

While there is a need for placebo-controlled treatment trials in SCH children looking at neurocognitive functioning and lipid levels, given the negative or inconclusive outcomes of such studies in adults, where it is far easier to study large numbers of patients, it does not seem likely that such studies in children would provide strong evidence in favor of treatment. Thus with the information currently available, the following suggestions for how SCH could be managed are proposed. 
(1) When screening for thyroid disease, primary care physicians should be advised to only order a free T4 and TSH. T3 uptake, T3, and free T3 add cost and are often abnormal in the absence of thyroid disease. There is controversy as to how helpful thyroid antibodies are as a screening test, since they are often positive in normal children, though less often than in adults. For example, in the NHANES III study in the US, $13 \%$ of the total population had thyroid peroxidase, and $11.5 \%$ had thyroglobulin antibodies; for the subset of 12-19 year olds (children under 12 were not included), the figures were $4.8 \%$ and $6.3 \%$, with higher rates of positivity in females than in males [31].

(2) A normal total or free T4 with a TSH of 5-10 mU/L is generally not the cause of whatever symptoms prompted the ordering of the thyroid tests in the first place, since it is the decrease in free T4 not increased TSH, which results in hypothyroid symptoms. Different patients have different set points for free T4, so that a child with a free T4 of $1.1 \mathrm{ng} / \mathrm{dL}(0.9-1.5)$ and TSH $2.0 \mathrm{mU} / \mathrm{L}$ is euthyroid, while another patient with free T4 $1.1 \mathrm{ng} / \mathrm{dL}$ and TSH $30 \mathrm{mU} / \mathrm{L}$ presumably once had a higher free T4, now has a failing thyroid gland and needs treatment. Nonetheless, few patients experience classic symptoms of hypothyroidism until their free T4 falls below the population normal range.

(3) If there is a goiter or the TSH is $>10 \mathrm{mU} / \mathrm{L}$, treatment is more likely to be indicated, as the odds of underlying thyroid disease are greater. While there are no pediatric studies which make this point clear, one study of adults older than age 55 calculated the progression of SCH to $\mathrm{OH}$ as 1.76 cases per 100 patient yearly with an initial TSH of 5.0-9.9, 19.67 for an initial TSH 10-14.9, and 73.47 for an initial TSH 15.0-19.9 [32]. In the same study, having a goiter increased the odds of progression to $\mathrm{OH}$ by a factor of 2.47 .

(4) If there is no goiter and TSH is $<10$, repeat free T4 and TSH is suggested in 6-12 months. Repeating the tests within a month, as is often done, usually results in a TSH similar to the initial one and provides no new information. By waiting 6-12 months, one allows time for either normalization of TSH or progression to $\mathrm{OH}$. It may be more helpful to measure thyroid antibodies with the second free T4 and TSH than as a screening test. If they are negative, it would provide reassurance that one is likely not dealing with AIT and would decrease the need for subsequent testing, while strongly positive antibody levels would signal the need for closer monitoring of thyroid tests.

(5) Further studies are needed to answer the question of how long one needs to monitor TSH in a child with $\mathrm{SCH}$ to make sure he or she has not progressed to $\mathrm{OH}$. It is proposed that TSH be rechecked periodically for 2 years (longer if there is a goiter or strongly positive antibodies). If the TSH remains in the $5-10 \mathrm{mU} / \mathrm{L}$ range, the child could be considered to have a stable mild TSH elevation and not require repeat testing unless a goiter appears, or there are new symptoms suggestive of $\mathrm{OH}$.

(6) Since a child with TSH 5-10 mU/L, no goiter, and negative antibodies is unlikely to progress to $\mathrm{OH}$, it is difficult to justify treatment. Even though an occasional child in this group will develop symptomatic $\mathrm{OH}$ during follow-up, long-term outcome is not improved by "catching it early." In the less common situation when free $\mathrm{T} 4$ is normal but TSH is $10-15$, progression to $\mathrm{OH}$ is more likely, particularly if there is evidence of AIT. Treating such patients seems reasonable, but periodic monitoring off therapy should also be an option.

(7) For children in the first 2 years of life with a clearly normal free T4 but mild persistent TSH elevation, the risk of developmental delay by withholding treatment should be very small, as AIT and progression to $\mathrm{OH}$ at this age appear to be rare. If a decision is made to treat and the TSH remains $<5 \mathrm{mU} / \mathrm{L}$, a one-month trial off l-thyroxine for reevaluation of thyroid status around the age of 3 years is suggested.

\section{Conclusion}

$\mathrm{SCH}$ is a very common finding in children, and several etiologies have been identified. Natural history studies indicate that over time, the majority of elevated TSH levels either revert to normal or remain mildly elevated. Children with persistent TSH elevation may be viewed as normal variants in which there is a stable equilibrium allowing normal thyroid hormone production in the presence of mild TSH elevation. The number of cases in which progression to $\mathrm{OH}$ has been small in all studies was reviewed, so occasional monitoring rather than immediate treatment may be the preferred strategy. Studies on children with mutations of the TSH-receptor suggest that some $\mathrm{SCH}$ patients without features of AIT may have increased TSH due to thyroid resistance to the effect of TSH. Preliminary studies suggest that treatment of SCH has no beneficial effect on growth, but additional studies are needed to determine if there are any measurable benefits (aside from the lowering of TSH) to treating such children with l-thyroxine.

\section{Abbreviations}

SCH: Subclinical hypothyroidism

OT: Overt hypothyroidism

AIT: Autoimmune thyroiditis

TSH: Thyroid stimulating hormone

TSH-R: TSH-receptor.

\section{References}

[1] G. Papi, E. D. Uberti, C. Betterle, et al., "Subclinical hypothyroidism," Current Opinion in Endocrinology, Diabetes and Obesity, vol. 14, no. 3, pp. 197-208, 2007. 
[2] T. Reinehr, A. Hinney, G. de Sousa, F. Austrup, J. Hebebrand, and W. Andler, "Definable somatic disorders in overweight children and adolescents," Journal of Pediatrics, vol. 150, no. 6, pp. 618-622, article e5, 2007.

[3] L. Lazar, R. B.-D. Frumkin, E. Battat, Y. Lebenthal, M. Phillip, and J. Meyerovitch, "Natural history of thyroid function tests over 5 years in a large pediatric cohort," Journal of Clinical Endocrinology and Metabolism, vol. 94, no. 5, pp. 1678-1682, 2009.

[4] D. Leonardi, N. Polizzotti, A. Carta, et al., "Longitudinal study of thyroid function in children with mild hyperthyrotropinemia at neonatal screening for congenital hypothyroidism," Journal of Clinical Endocrinology and Metabolism, vol. 93, no. 7, pp. 2679-2685, 2008.

[5] M. Wasniewska, M. Salerno, A. Cassio, et al., "Prospective evaluation of the natural course of idiopathic subclinical hypothyroidism in childhood and adolescence," European Journal of Endocrinology, vol. 160, no. 3, pp. 417-421, 2009.

[6] D. C. Moore, "Natural course of 'subclinical' hypothyroidism in childhood and adolescence," Archives of Pediatrics and Adolescent Medicine, vol. 150, no. 3, pp. 293-297, 1996.

[7] G. Radetti, E. Gottardi, G. Bona, A. Corrias, S. Salardi, and S. Loche, "The natural history of euthyroid Hashimoto's thyroiditis in children," Journal of Pediatrics, vol. 149, no. 6, pp. 827-832, 2006.

[8] A. Fava, R. Oliverio, S. Giuliano, et al., "Clinical evolution of autoimmune thyroiditis in children and adolescents," Thyroid, vol. 19, no. 4, pp. 361-367, 2009.

[9] P. B. Kaplowitz and R. Mehra, "Outcome of children with presumed hypothyroidism when selectively taken off thyroid hormone," in Proceedings of the 91st Annual Meeting of the Endocrine Society, Washington, DC, USA, June 2009.

[10] D. Rubello, G. B. Pozzan, D. Casara, et al., "Natural course of subclinical hypothyroidism in Down's syndrome: prospective study results and therapeutic considerations," Journal of Endocrinological Investigation, vol. 18, no. 1, pp. 35-40, 1995.

[11] L. Gruñeiro de Papendieck, A. Chiesa, M. G. Bastida, G. Alonso, G. Finkielstain, and J. J. Heinrich, "Thyroid dysfunction and high thyroid stimulating hormone levels in children with Down's syndrome," Journal of Pediatric Endocrinology and Metabolism, vol. 15, no. 9, pp. 1543-1548, 2002.

[12] M. Tonacchera, A. Perri, G. De Marco, et al., "TSH receptor and Gs $\alpha$ genetic analysis in children with Down's syndrome and subclinical hypothyroidism," Journal of Endocrinological Investigation, vol. 26, no. 10, pp. 997-1000, 2003.

[13] C. H. Konings, A. S. P. van Trotsenburg, C. Ris-Stalpers, T. Vulsma, B. M. Wiedijk, and J. J. M. De Vijlder, "Plasma thyrotropin bioactivity in Down's syndrome children with subclinical hypothyroidism," European Journal of Endocrinology, vol. 144, no. 1, pp. 1-4, 2001.

[14] P. Cambiaso, C. Orazi, M. C. Digilio, et al., "Thyroid morphology and subclinical hypothyroidism in children and adolescents with Williams syndrome," Journal of Pediatrics, vol. 150, no. 1, pp. 62-65, 2007.

[15] R. L. Schaub, D. E. Hale, S. R. Rose, R. J. Leach, and J. D. Cody, "The spectrum of thyroid abnormalities in individuals with 18q deletions," Journal of Clinical Endocrinology and Metabolism, vol. 90, no. 4, pp. 2259-2263, 2005.

[16] M. T. McDermott and E. C. Ridgway, "Subclinical hypothyroidism is mild thyroid failure and should be treated," Journal of Clinical Endocrinology and Metabolism, vol. 86, no. 10, pp. 4585-4590, 2001.

[17] J. W. Chu and L. M. Crapo, "The treatment of subclinical hypothyroidism is seldom necessary," Journal of Clinical
Endocrinology and Metabolism, vol. 86, no. 10, pp. 4591-4599, 2001.

[18] H. Gharib, R. M. Tuttle, H. J. Baskin, L. H. Fish, P. A. Singer, and M. T. McDermott, "Consensus statement: subclinical thyroid dysfunction: a joint statement on management from the American Association of Clinical Endocrinologists, the American Thyroid Association, and the Endocrine Society," Journal of Clinical Endocrinology and Metabolism, vol. 90, no. 1, pp. 581-585, 2005.

[19] M. I. Surks, "Commentary: subclinical thyroid dysfunction: a joint statement on management from the American Association of Clinical Endocrinologists, the American Thyroid Association, and the Endocrine Society," Journal of Clinical Endocrinology and Metabolism, vol. 90, no. 1, pp. 586-587, 2005.

[20] M. P. J. Vanderpump, W. M. G. Tunbridge, J. M. French, et al., "The incidence of thyroid disorders in the community: a twenty-year follow-up of the Whickham Survey," Clinical Endocrinology, vol. 43, no. 1, pp. 55-66, 1995.

[21] T. Wu, J. W. Flowers, F. Tudiver, J. L. Wilson, and N. Punyasavatsut, "Subclinical thyroid disorders and cognitive performance among adolescents in the United States," BMC Pediatrics, vol. 6, article 12, 2006.

[22] N. J. Aijaz, E. M. Flaherty, T. Preston, S. S. Bracken, A. H. Lane, and T. A. Wilson, "Neurocognitive function in children with compensated hypothyroidismml: lack of short term effects on or off thyroxin," BMC Endocrine Disorders, vol. 6, article 2, 2006.

[23] V. L. Zen, M. A. Czepielewski, L. P. de Paula, and J. C. Schwerz, "Subclinical hypothyroidism prevalence in children evaluated for short stature," in Proceedings of the 91st Annual Meeting of the Endocrine Society, Washington, DC, USA, June 2009.

[24] V. L. Zen, M. A. Czepielewski, L. P. de Paula, and J. C. Schwerz, "Thyroxin replacement therapy does not improve growth velocity in children with subclinical hypothyroidism and short stature," in Proceedings of the 91st Annual Meeting of the Endocrine Society, Washington, DC, USA, June 2009.

[25] R. R. Scobbo, T. W. VonDohlen, M. Hassan, and S. Islam, "Serum TSH variability in normal individuals: the influence of time of sample collection," The West Virginia Medical Journal, vol. 100, no. 4, pp. 138-142, 2004.

[26] A. Keselman, A. Chiesa, S. Malozowski, A. Vieytes, J. J. Heinrich, and L. Gruñeiro de Papendieck, "Abnormal responses to TRH in children born small for gestational age that failed to catch up," Hormone Research, vol. 72, no. 3, pp. 167-171, 2009.

[27] S. Chikunguwo, S. Brethauer, V. Nirujogi, et al., "Influence of obesity and surgical weight loss on thyroid hormone levels," Surgery for Obesity and Related Diseases, vol. 3, no. 6, pp. 631635, 2007.

[28] A. Rapa, A. Monzani, S. Moia, et al., "Subclinical hypothyroidism in children and adolescents: a wide range of clinical, biochemical, and genetic factors involved," Journal of Clinical Endocrinology and Metabolism, vol. 94, no. 7, pp. 2414-2420, 2009.

[29] S. Narumi, K. Muroya, Y. Abe, et al., "TSHR mutations as a cause of congenital hypothyroidism in Japan: a population-based genetic epidemiology study," Journal of Clinical Endocrinology and Metabolism, vol. 94, no. 4, pp. 1317-1323, 2009.

[30] A. Nicoletti, M. Bal, G. De Marco, et al., "Thyrotropinstimulating hormone receptor gene analysis in pediatric patients with non-autoimmune subclinical hypothyroidism," Journal of Clinical Endocrinology and Metabolism, vol. 94, no. 11, pp. 4187-4194, 2009. 
[31] J. G. Hollowell, N. W. Staehling, W. D. Flanders, et al., "Serum TSH, T, and thyroid antibodies in the United States population (1988 to 1994): National Health and Nutrition Examination Survey (NHANES III)," Journal of Clinical Endocrinology and Metabolism, vol. 87, no. 2, pp. 489-499, 2002.

[32] J. J. Díez and P. Iglesias, "Spontaneous subclinical hypothyroidism in patients older than 55 years: an analysis of natural course and risk factors for the development of overt thyroid failure," Journal of Clinical Endocrinology and Metabolism, vol. 89, no. 10, pp. 4890-4897, 2004. 